\title{
REFLECTION
}

\section{Does demography need differential equations? ${ }^{1}$}

\author{
Thomas K. Burch \\ Population Research Group, University of Victoria \\ tkburch@uvic.ca
}

\begin{abstract}
The starting point for this essay is the observation — partly impressionistic — that demography as a discipline has tended to neglect the predator-prey equations in courses, textbooks, compendia, and research papers. This is surprising, since the equations bear the name of A. J. Lotka, one of the acknowledged founders of modern demography. This relative neglect is unfortunate, since a central fact about the human species is that we are deeply implicated in nature as both predator and prey. Possible explanations for this situation are discussed, including a general neglect of systematic theory, and of differential equations, a branch of mathematics especially suited to the statement and exploration of theories of demographic processes.
\end{abstract}

Keywords: demography, differential equations.

\section{Résumé}

Cet article se base sur une observation - quelque peu impressionniste - que la démographie en tant que discipline a tendance à négliger les équations prédateurs-proies dans leurs cours, manuels, recueils, et articles de recherche. Ceci est surprenant puisque les équations portent le nom d'A. J. Lotka, un des fondateurs reconnus de la démographie moderne. Cette omission sommaire est malencontreuse puisqu'un des éléments principaux de la race humaine est que notre relation avec la nature est profondément liée aux dynamiques de prédateur et de proie. Diverses explications pour cette situation sont étudiées, y compris l'omission générale de la théorie systémique, et des équations différentielles comme outil scientifique, qui se prête particulièrement bien à la théorisation.

Mots-clés : démographie, équations différentielles.

1. This is a revised version of a presentation at the Center for Studies in Demography and Ecology (University of Washington, Seattle, 20 February 2004) in a seminar series on modelling and simulation, organised by Martina Morris. It was repeated for seminars at the Universities of Rome (La Sapienza) and of Padua in June 2007. 


\section{Introduction}

The predator-prey equation is one of the most famous differential equations of all time. It is central to discussions of population growth in population biology, and appears regularly in application-oriented textbooks on differential equations. It figures prominently in the work of one of the founders of modern demography, A. J. Lotka. Indeed, another name for the model is the Lotka-Volterra equation, after its co-discoverers. ${ }^{2}$

More profoundly, as applied to the humans, it is a reminder that we too are part of nature - as both predator and prey. The model does not apply strictly to humans, since as omnivores we have escaped the fate of species dependent on a single food supply. Nor are we successfully singled out as prey — a preferred food source-for some other species. But the model is embedded in our population dynamics. An argument could be made that our predatory behaviour has been both a cause and a result of our long-term sustained population growth. And indeed there have been occasions when human populations were decimated by micro-organisms, notably the Black Death in the 14th century and HIVAIDS in some parts of Africa today.

Despite all this, the predator-prey model is seldom discussed in contemporary demographic literature, whether textbooks, compendia, or research papers. What is the explanation for this neglect of such an important theoretical population model?

This essay attempts a tentative answer by discussing two related questions:

The first question is: Why has demography made relatively little use of differential equations? I take the fact as evident, but give some specifics in the next section. The question relates to demography as a whole, not just to the highly specialised sub-field of mathematical demography, where of course the use of differential equations is more common, although not as common as one might suppose. The question assumes that differential equations should be and are a basic tool in empirical science, and that demography is or aspires to be an autonomous science, not just a branch of applied statistics. The former assumption will be re-visited later; the latter assumption, I believe, should not require further discussion.

The second question is a more specific version of the first: Why has demography made so little use of modern software - readily available and easy to use-for the modelling of complex dynamic systems with feedback? I am thinking of software such as Dynamo, Stella, Vensim, and Modelmaker. Designed to provide numerical solutions to systems of differential/difference equations, this software provides an accessible scientific tool for those with limited grounding in mathematics. Again, it seems evident that systems dynamics software is rarely used by demographers.

These questions identify gaps in our discipline of demography, gaps that ought to be filled. The relative absence of the use of standard differential equations strikes me as difficult to remedy, since it relates to a fairly deep and widespread lack of mathematical training of demographers, and a lack of early training is not easily made up later. (I am speaking here mainly of North American demography, since the situation in, say, Italy or France is different. And I am speaking mainly of general demography and social demography rather that economic demography, where mathematical theory and simulation are much further developed.)

2. Vito Volterra (1860-1940) was an Italian mathematician and physicist known for his contributions to population biology and to the study of integral equations. 
The failure to use systems dynamics software would be relatively easy to remedy, since it is designed to be user-friendly, and requires little in the way of mathematical sophistication. Computer mathematics packages such as Maple, Mathematica, Derive, and Mathcad, which include routines for solving differential equations, can also help in this regard. But they assume a higher level of mathematical competence.

The basic remedy lies in the training of future demographers. Again, impressionistically it seems to me that general mathematical training and computer modeling/simulation specific to social science do not yet occupy the place they deserve in our demographic curricula, whether undergraduate or graduate. This, in turn, is related to contemporary demography's preoccupation with statistical modeling of census and survey data, and a relative neglect of substantive theoretical models. ${ }^{3}$

\section{Predator-prey and other differential equations in demographic literature}

\section{Predator-prey}

A JSTOR search of 24 population studies journals on the terms 'predator-prey' and 'Lotka-Volterra' yields less than two dozen citations. In most of these, the term or concept is discussed only in passing. In a few cases, predator-prey equations are used to study the interactions between two human populations (Keyfitz 1965; Hudson 1970). Keyfitz, in a study of marriage and the two-sex problem in population models, begins with a quote from Volterra to the effect that the study of a population in isolation “... is inadequate, no matter how elaborate the model may be, when the population in question is in effective ecological contact with some other population" (Keyfitz 1965: 276). Hudson uses the predator-prey model to study population growth and migration in a two-region (metropolitan/non-metropolitan) system. Interestingly, his paper makes considerable use of differential equations, but Hudson is a geographer, not a demographer. The JSTOR search reveals virtually no articles dealing at length with the interactions of humans with non-human species.

The neglect of the predator-prey equation in demography is a special case of a broader neglect of the use of differential equations, as is evident from a quick survey of the literature.

\section{Differential equations in texts}

Demography is not particularly rich in textbooks, since publishers are reluctant to deal with a relatively small undergraduate market. Nevertheless, a review of a fair sample of recent and older works turns up few instances of the use of differential equations. This is so of "substantive" texts, such as John Weeks' popular undergraduate text, but it also is true of more 'technical' works. One searches in vain for differential equations

3. This problem is neither new nor confined to demography. The British biologist Maynard Smith commented in 1968: "It is widely assumed-particularly by statisticians-that the only branch of mathematics necessary for a biologist is statistics. I do not share this view... I am concerned with those branches of mathematics-primarily differential equations, recurrence relations and probability theory — which can be used to describe biological processes" (Smith 1968: 1). On the respective roles of theoretical computer models and statistical models in demography, see Burch (2005). 
in older works, such as Barclay's Techniques of Population Analysis or Shryock and Siegel's Methods and Materials of Demography.

An authoritative recent work is that of Preston, Heuveline, and Guillot (2001). They present differential equations in only a few places, notably in discussing exponential growth and the force of mortality. Exceptions may be found in specialized works by mathematical demographers, or many issues of Mathematical Population Studies. But, as noted earlier, this body of work stands somewhat apart from the demographic mainstream — substantive demography, especially behavioral demography — whereas differential equations appear to be central to substantive exposition in many other disciplines.

\section{Differential equations in journal articles}

There are only a handful of mainline demographic papers in which differential equations play a central role, or even appear. A notable exception is an old paper by Hernes (1972) on marriage. Hernes developed a differential equation of the first marriage curve, based on behavioural assumptions of: (a) some initial level of "marriageability;" (b) an exponential decline of marriageability with age; (c) pressure to marry based on the proportion in a cohort already married; and (d) limits to marriage due to declining availability of partners. His behavioural reasoning led to a relatively simple and easily understood differential equation. The behavioural assumptions have become outmoded by subsequent events (notably the rise of extramarital sex, divorce, and cohabitation), but it was a strong beginning. However, the Hernes model was largely ignored by demographers, with only a few exceptions, and the Coale-McNeil model (Coale and McNeil 1972) became canonical. ${ }^{4}$ I compared the two in a 1993 paper (Burch 1993), noting that Hernes' model was more elegant, fit cohort data just as well, and had more behavioural content. Later research by Francesco Billari showed that it also was more robust for the projection of incomplete cohort data.

Another example is a paper by Rosero-Bixby and Casterline (1993) on fertility decline in Costa Rica. They develop a differential equation model for the diffusion of family planning use, and its impact on fertility over time. It is essentially a compartment model, with women moving from non-motivated to motivated but not using family planning, to using family planning, with elements of point-source and interaction diffusion in variants of the basic model. Their paper is cited occasionally, but does not seem to have inspired replication or further development.

I'm sure more examples could be found, but they are not commonplace. As a rule, quantitative articles consist of statistical analysis of data, and theoretical articles are not stated in rigorous, formal language — the few that have been are more apt to resort to formal logic than to mathematics and tend to be relatively static.

\section{Lotka's patrimony}

Many demographers, especially mathematical demographers, would agree that Alfred J. Lotka is one of the founders of modern demography. And although we claim to be his intellectual descendants, it is interesting how little of his scientific patrimony we have accepted-stable population theory, reproduction rates, and, more recently, the

4. It is worth noting that Hernes' paper did not appear in an obscure journal but rather in The American Sociological Reviem, one of the leading sociological journals. 
Figure 1. Lotka's system of differential equations.

\section{CHAPTER 4}

\section{Biological Stoichiometry}

Recognizing that at every instant the rate of increase of each species in the system being studied depends on the quantity of that species and of every other species present, as well as the parameters $P$ and $Q$, we have already noted that the analytical expression of this very general proposition takes the form:

$$
\left.\begin{array}{rl}
\frac{d X_{1}}{d t}= & F_{1}\left(X_{1}, X_{2}, \ldots, X_{n} ; P, Q\right) \\
\frac{d X_{2}}{d t}= & F_{2}\left(X_{1}, X_{2}, \ldots, X_{n} ; P, Q\right) \\
& \ldots \\
\frac{d X_{i}}{d t}= & F_{i}\left(X_{1}, X_{2}, \ldots, X_{n} ; P, Q\right) \\
& \ldots \\
\frac{d X_{n}}{d t}= & F_{n}\left(X_{1}, X_{2}, \ldots, X_{n} ; P, Q\right)
\end{array}\right\}
$$

We have also noted that when we are considering a relatively short period of observation we can often neglect the changes in the parameters $Q$ which express intra-species changes in form that occur very slowly. We then address what we will call "pure inter-species evolution." In addition, we may be specifically interested in the special case in which the general conditions of the system (climate, topography, etc.) remain

\footnotetext{
- Alongside these essential changes in the basic character of the species, we will also have to consider certain more or less adventitious changes, that is, more or less superficial changes such as those in the age distribution of the individuals of the species. We will see later that in certain cases the effect of these changes reenters without difficulty into our analysis. It must be acknowledged that in other cases it introduces rather formidable complications. For the moment, we will neglect this factor.
}

Source: Lotka 1934/1939: 31.

demography of kinship, inspired by his pioneering work on estimating the prevalence of orphanhood by age. Much else has been left behind.

Lotka the polymath

Lotka, of course, was not just a demographer. His early training was in the physical sciences, primarily chemistry and biology. He became active in demographic circles later on, including early meetings of the IUSSP. His work best known to demographers is entitled Demographic Analysis, With Special Reference to the Human Species (transl. from the 
French). This monograph is in fact the second part of a larger work entitled Analytic Theory of Biological Associations. The first part, seldom referenced by demographers, is entitled simply Principles (see Lotka 1934/1939).

On p. 8 of Principles one encounters the differential equation

$$
d X_{i} / d t=F_{i}\left(X_{1}, X_{2}, \ldots, X_{n}, P, Q\right) .
$$

Lotka introduces it as a general statement of the principle that the rate of increase of any component in a system is a function of the quantity of all other components in the system plus parameters defining the characteristics of each component $(P)$, as well as other parameters $(Q)$ that "serve to complete the definition of the state of the system" (Lotka 1934: 7).

A little later on, Lotka begins a chapter entitled "Biological Stoichiometry" with the following statement, introducing a system of differential equations: "In asserting that at each instant the rate of growth of each species in the system depends on the size of that species and of all the other species present, as well as on parameters $P$ and $Q$, we have already noted that the analytic expression of this very general proposition takes the form..." A system of $n$ differential equations follows (see Fig. 1). On the next page, the system is abbreviated by dropping the parameters on the grounds that the characteristics of species change little over a reasonably short period, as do those of the environment"climate, topography, etc." (Lotka 1934: 32-3).

Here, the human species is firmly embedded in a biological system consisting of many other species. His framework is essentially a systems framework. The scope of the systems he envisions is shown in a complex diagram of the interrelations of fish populations and their food supplies. Lotka was thinking in terms of systems well before the systems concept became popular to the point of being faddish, thirty or so years later.

Later in the chapter, he presents equations for two species in interaction, the "predator-prey equations," and develops an expression for the logistic curve (then thought of as a "law" of population growth). In every case, the development is in terms of differential equations, sometimes leading to an analytic solution, sometimes not. But the differential equations frame the discussion.

In his earlier work, Elements of Physical Biology (1924, republished in 1956 as Elements of Mathematical Biology), some of these ideas are developed in greater detail, including the extension of the two-interacting-species model to three or more, ${ }^{5}$ as well as a description of several types of two-species interaction other than as predator-prey-one of his examples relates to humans' relationship to domestic animals such as cattle and poultry, which we breed as well as nurture and eat.

\section{Lotka the human demographer}

In the second part of Analytic Theory..., Lotka begins:

Species exist in mutual relationships with one another, such that it is true to say that it would be impossible to make a well-rounded study of a species without taking account of the large number of other species which influence it in one way or another (Lotka 1939: 5).

5. Stella, student-oriented systems dynamics software, provides an interesting game in which the student is challenged to bring three interacting populations (deer, wolves, and grass) into equilibrium. The near impossibility of doing so is a powerful demonstration of the effects of non-linearity in systems. 


\section{He continues:}

However, there exist among the internal factors of a population of living beings [such as natality, mortality, growth, etc.] a large number of relationships which permit and even demand a special study, without the necessity at each step of taking explicit account of other species occupying the same locale. This study, in fact, constitutes a well-defined body of research and of results, which we take up in the present volume, with particular attention to the human species, for which we possess an abundance of data (Lotka 1939: 5).

Lotka divides the study of human populations into two parts. One he terms demographic analysis, a branch of mathematics (i.e., analysis) applied to human population dynamics, to discover and state necessary relations among demographic variables. He distinguishes this from a second part of demography, which he calls statistical demography, the statistical study of relationships among demographic variables. The two branches seem to be related as theory and empirical research.

\section{Lotka the theorist}

Lotka assumes the importance of empirical research — he is, after all, a scientist - but clearly thinks it is not enough:

... one will find more satisfying to the spirit that knowledge more complete, or at least deeper, which one obtains when one has succeeded in taking account of not only the empirical relationships, whose physical causes and logical reasons escape us ... but also the necessary relationships [imposed by the laws of logic and of physics] among the quantities describing the state of and the changes in a population (Lotka 1939: 6).

It appears that Lotka was at heart a theorist. And he considers differential equations to be a fundamental tool of theory. In Elements of Mathematical Biology, he writes:

In the language of the calculus, the differential equations display a certain simplicity of form, and are therefore, in the handling of the theory at least, taken as the starting point, from which the equations relating to the progressive states themselves, as functions of the time, are then derived by integration (Lotka 1956: 42).

He adds in a footnote: "In experimental observation usually (though not always) the reverse attitude is adopted." Demography typically uses the integral rather than the original differential equation.

The Hernes model mentioned earlier provides a nice illustration. The differential equation is simple and transparent. Its integral, giving proportion married by age in a cohort, is more complicated and harder to intuit, but more useful for fitting cohort data on proportions married by age.

One wonders whether Lotka contemplated a third part to Analytic Theory..., which would have revisited his system of equations, discussed at length in the earlier monograph, in order to study relationships between human populations and other species. But it is clear that demography has focused on the more limited study of human population as defined above. In doing so, we have left behind a large part of Lotka's complete intellectual heritage, including: (a) a strong emphasis on theory as well as empirical, statistical research; (b) regular use of differential equations as a natural tool for the theoretical study of process; and (c) the study of the interrelationship between human and non-human populations. 
A student of demography could go far in the field without ever being taught to think of the human species as both predator and prey. We study diseases as causes of death, not as a manifestation of micro-organisms using human bodies as habitat. We study fish as a natural resource, not so much as a population on which we prey, although this is changing with the disappearance of many stocks. Joel Cohen notes in a paper on population projections: "Other species are recognized explicitly only in the recent innovation of quantifying the devastating impacts of HIV and AIDS" (2003: 1172).

As noted above, Hernes and Rosero-Bixby and Casterline used differential equations to study processes and systems that demographers study regularly-cohort behaviour, multi-state systems, and diffusion. Lotka and others (notably biological ecologists) use them to study processes and systems that we have largely ignored.

In other cases, we have studied certain systems, but only in a limited, technical way. The logistic model is a case in point. In ecology and in differential equations texts, it is introduced as a differential equation. In demography, it typically is presented simply as a mathematical curve (the analytic solution of the differential equation), invariably identified as a technique for population projection. As such, it is rejected in favour of the standard cohort-component technique, partly on the grounds that it only deals with total population, not with the components of growth. In an obvious sense this is partly so, but in another sense it is not. When ecologists (e.g., Wilson and Bossert 1971) discuss the logistic curve, it is derived from assumptions relating to the relationships among population density, fertility, and mortality. In demography, the logistic is simply a mathematical function. In ecology, it is a theoretical model.

What is the explanation for our relative lack of interest in multi-species models? Human ethnocentrism, perhaps? There is a large element of exceptionalism in our view of our place in the natural world. Or does it have something to do with the fact that a large proportion of practicing demographers, especially social demographers, have been innocent of differential equations, even the low level of knowledge necessary to understand the predator-prey equations.

Other disciplines, notably biological ecology or population biology, have continued to develop Lotka's insights and equations, including the systematic study of inter-species relationships; Gotelli's recent text (1998), for example, devotes about 50 out of 200 pages to the topic.

\section{Abbot on Coleman vs. Blalock}

Andrew Abbot, in his stimulating paper entitled "Transcending general linear reality" (1988) suggests a similar neglect of differential equations as a tool in empirical sociology. He notes the domination of quantitative sociology by the use of multivariate statistical analysis based on the general linear model. In a footnote, he compares citations to Blalock's 1960 text Social Statistics (featuring the use of regression) and to Coleman's 1964 text Introduction to Mathematical Sociology (featuring the use of differential equations). In the period 1966-70, there were 162 citations of Blalock vs. 117 of Coleman; by 1980, it was 117 vs. 24, and by 1984, it was 104 vs. 15 . He notes that Coleman's work has never been reprinted. He attributes the dominance of regression analysis to its "commodification" in easy-to-use packages such as SPSS.

Abbot makes the useful distinction between the "representational" interpretation of regression models ("My model represents the social system") and the "entailment" 
interpretation ("If my theory is correct, then I should get certain results in my regression model"). One is largely descriptive of relationships among measured variables; the other is oriented towards testing theory. Abbot considers the representational interpretation a case of reification, the positing of a "general linear reality" based on a highly abstract empirical model.

Blalock presented regression clearly as a tool of empirical research (although, in keeping with the logical empiricist doctrine of the time, he viewed the resulting empirical generalisations as "laws," and therefore as the essential foundation blocks for theory). Coleman tends to see differential equations as a theoretical tool used to 'represent' dynamic systems.

Either tool can be used in Abbot's entailment mode.

The impact of "commodification" is difficult to judge. But it is worth noting that the commodification of differential equations also occurred relative early-Dynamo was developed in the 1960s and became commercially available soon after. In the same year as Abbott wrote, Robert Hanneman published a book urging sociologists to consider Dynamo as a tool for modeling dynamic social systems (1988). And the major mathematical software packages (Mathematica, Maple, Mathcad, etc.) regularly expanded their utilities for solving differential equations. Why did empirical sociology and demography buy so much of the one commodity and not the other?

Several possible answers to the first question suggest themselves:

1. Differential equations are not necessary or particularly useful for the study of most issues of greatest interest to demographers. Other analytic methods have been more fruitful.

2. The average demographer has little competence in the use of differential equations. That level of mathematics has not been required for entrance into, or successful completion of, most graduate programs.

3. Demography has avoided substantive areas that essentially require the use of differential equations, including non-linear equations.

4. Differential equations are more a theoretical than an empirical tool, and demographers have never given high priority to theory, as opposed to data and techniques.

I would argue that \#1 is questionable. Why should a tool that has proven so fruitful in other sciences be of little use to demography? Answer \#2 lies at the heart of the problem: Demographers generally were not schooled in differential equations, so they didn't try to use them, and avoided topics that required their use even at the most elementary level (as with predator-prey).

\section{Systems dynamics software}

In light of \#2 in the previous section, one can ask a second question: Why has demography not taken advantage of systems dynamics software? It enables the mathematically challenged to construct and work with models of complex systems with feedbacks. And it necessarily orients thinking towards dynamics and process, not just cross-sectional recursive relationships.

This software, to the best of my knowledge, began with the early work of an engineer, Jay Forrester, to apply engineering principles of feedback and control to social sys- 
tems. His first work, Industrial Dynamics, was published in 1961. World Dynamics appeared in 1971 and became the basis for the influential and controversial book The Limits to Growth by Meadows and Meadows (1972). The MIT systems dynamics school has generated a large literature, both general works and simulations of particular systems, and has helped stimulate the development of other software with similar structure and aims. These include Stella, Dynamo, Modelmaker, Vensim, and no doubt others.

It is characteristic of much of the literature of the MIT group that more attention is paid to the building of models than to their relationship to the real world. A basic hardback text from the MIT group (Roberts et al. 1983), for example-a work of over 500 pages - contains no chapter on testing, validation, parameter estimation, or goodness of fit; indeed, these words don't even appear in the index. This exclusion apparently is deliberate. The authors include "model evaluation" as one of the phases in the model-building process, and comment:

... [N]umerous tests must be performed on the model to evaluate its quality and validity. These tests range from checking for logical consistency to matching model output against observed data collected over time, to more formal statistical tests of parameters used within the simulation. Although a complete discussion of model evaluation is beyond the scope of the book, some of the important issues involved are presented in the case examples... (Roberts et al. 1983: 9).

The main technique of model evaluation is the demonstration that the model fits one or more empirical time series of outputs. If the model can generate the output reasonably closely, then it is considered a good model. But it is not "proven," of course. To assume so is to commit the fallacy of affirming the antecedent.

Whatever the intent, it is hard for the reader to avoid the impression that evaluating a model's fit to real world, or at least to data, is less interesting and less important than building the model.

An earlier work from the same group makes clear that the emphasis on model building rather than model estimation or testing goodness of fit reflects a deep-seated attitude towards scientific and policy analysis, one somewhat at odds with traditional statistical methodology:

The systems dynamics approach to complex problems ... takes the philosophical position that feedback structures are responsible for the changes we experience over time. The premise is that dynamic behavior is the consequence of system structure (Richardson and Pugh 1981: 15).

That is, if one has the structure right, the details (e.g., specific parameter values) don't matter so much. And later:

... experience with feedback models will convince the reader that model behavior really is more a consequence of structure than parameter values. One should therefore be more concerned with developing the arts of conceptualization and formulation than finding ultimate parameter selection methods. Our advice for beginners would be to estimate parameters with good statistics [data] but not Statistics [mathematical methods]. In the systems dynamics context the latter are a collection of power tools that just might cut off your intuition (Richardson and Pugh 1981: 240). 
In general, they are skeptical about the value of correlational approaches and standard regression techniques (ordinary and generalized least-squares), especially when dealing with dynamic models with feedback (Richardson and Pugh 1981: 238-9).

Validating a model in this tradition, as noted above, is achieved primarily by comparison of model output of key variables with "reference behavior modes," essentially observed time-series measures of the phenomena of interest. But still, the greater emphasis is placed on causal understanding: how does the process really work? Regression equations, with coefficients attached to a set of distinct factors to reflect their relative importance, are viewed as uninformative, at least as a representation of process in an underlying system. In Abbott's words, they reject a "representational" approach to linear regression models in favour of an approach that they feel accords better with our intuition of how a system actually works (1988).

A later example in this tradition criticizes an econometric analysis of milk production, expressed as a function of GNP, interest rates, etc., on the grounds that the model nowhere mentions cows; and a model of human births (as a function of birth control, education, income, health, religion, etc.) on the grounds that the model nowhere mentions mothers (HPS 1996: 25-8). A contemporary text by Hannon and Ruth (1994) takes a more balanced and sophisticated approach towards blending dynamic modelling and more traditional statistical approaches, as do recent versions of systematic dynamics software. But much of the earlier literature seemed almost hostile to statistical research in the social sciences.

Some of the early substantive research by systems dynamicists left much to be desired and was heavily criticized by social scientists and others. Forrester's "world model," which was the basis for The Limits to Growth, is so complex that one wonders whether it can be meaningful. Certainly its operation is beyond an intuitive grasp, and it is so big that the risk of programming errors, functional misspecification, and wrong parameters must be large. Despite the size of the model, as my former colleague Tom Wonnacott constantly reminded me, the resource module contained no variable for price. Although a best-seller, The Limits to Growth was dismissed by many economists, demographers, and others.

There is a particular reason why demographers would be turned off by this body of work, namely, population projections are done in an unconventional way and use unconventional language. The absolute numbers of births and deaths flowing into and out of a population per unit of time are referred to as rates (per unit of time) - a perfectly good usage in calculus and common in ecology, but at odds with demographic usage. The relative numbers of births and deaths are referred to as fractional rates. And the number of deaths is calculated by dividing population by average lifetime, instead of using the crude death rate (the rough equivalence obtains, of course, only in the stationary population model). Instead of surviving an age group to the next older age group using survival ratios, age-groups remain in place, as it were, with deaths being subtracted, and population "aging in" from the age group below, and "aging out" to the age group above. For a five-year age group, for example, it is assumed that, apart from deaths, $1 / 5$ will move to the next-highest age group, with $1 / 5$ of the next-lowest age group moving in. The language and procedure strike the average demographer as improper, and suggest a lack of understanding of population dynamics. By convention, they are indeed incorrect, and a student who used this approach on a demographic techniques exam probably would get a failing grade. But in point of fact, given identical input, the systems dynamics pro- 
cedure can generate projections by age and sex that do not differ appreciably from those produced by the standard cohort-component projection technique. Both approaches, of course, contain approximations.

The intellectual history of all this remains to be written. But my impression is that some early excesses and some disciplinary rivalries (Forrester, after all, was an engineer who did not "convert" to economics or demography) gave a perfectly sound approach and its associated software a bad name. In talking to colleagues about Dynamo, I remember getting a distinct impression that reputationally it was "lower-class" software. But I think we may have thrown the baby out with the bathwater. And I find evidence from time to time that disciplines such as biology are using this software in research, and teaching it to students.

So why has demography — or sociology, for that matter-not taken greater advantage of these tools? In addition to the possible answers given earlier to the more general question, the following come to mind:

1. There are inherent flaws in the systems dynamics approach and associated software;

2. Demographers were put off by the exaggerated claims of early systems dynamics modelers, and by their seeming indifference, and even hostility, towards statistical research in the social sciences;

3. We dismissed their population models on the grounds that they did not use the "correct" approach and terminology, that is, the canonical approach in demography;

4. Quantitative social scientists in general often viewed systems modelling as secondrate empirical work, dealing with made-up numbers instead of hard data. Social theorists, on the other hand, assumed it was "number crunching," since it relied on the computer and dealt with numbers and quantitative relationships. As a result, a valuable tool fell through the cracks.

\section{Concluding comment}

Demography is a wonderful discipline. I have come to think of it as a better discipline than is generally recognized, because we have not codified and presented it in the most effective way. And clearly I think it might be an even stronger discipline if it had assimilated the regular use of differential equations in general, and systems dynamics software in particular. The latter would have allowed those of us who lack a thorough grounding in mathematics to work with relatively complex systems of differential equations. This is not just for the sake of using them, but to help us with thought processes that need help. Their use would encourage us to think more about dynamics and process, and not just cross-sectional relationships and equilibria. They could help us think better about complex social and demographic systems containing non-linear relationships and feedbacks. They could help us introduce more clarity in our theoretical models (for example, transition theory) typically stated in words and manipulated by everyday logic. And they could introduce these intellectual habits to our students—even sociology undergraduates who know almost no mathematics. 
The use of differential equations could also help us to extend our discipline to consider topics previously neglected. It would help us to develop a richer portfolio of population growth models, beyond the exponential, stable, projection, etc. We might begin to renew a serious interest in the logistic, which in the very long term may apply to human population after all. We could learn about the Allee effect ${ }^{6}$ from our biological cousins in ecology; in over forty years in the field, I had never heard about this in demography, yet it would seem to have relevance to our past and future. We would be better equipped to study interactions among humans and other species, to finally recognize and accept the fact that we are both predator and prey.

In all of this, we must get over a common confusion referred to several times above, a confusion of differential equation models with empirical work. They are not a substitute for statistical investigation, qualitative description, or other forms of empirical study. Rather they are a tool for the construction and exploration of the theory and theoretical models that attempt to explain our empirical findings. Demography is generally thought to be rich in data and technique, and poor in theory. I have suggested elsewhere (e.g., Burch 2003a, 2003b) that we have more and better theory than is generally thought. But our body of theory could be richer still if we were to take advantage of both classicdifferential equations - and contemporary_systems dynamics software-tools for the statement and manipulation of theoretical ideas about demographic processes.

\section{References}

Abbott, A. 1988. Transcending general linear reality. Sociological Theory 6:169-86.

Allee, W.C., A.E. Emerson, O. Park, T. Park, and K.P. Schmidt. 1949. Principles of Animal Ecology. Philadelphia: W.B. Saunders.

Blalock, H.M. 1960. Social Statistics. New York: McGraw-Hill.

Burch, T.K. 1993. Theory, computers and the parameterisation of demographic behaviour. IUSSP International Population Conference, Montreal 1993. Vol. 3. Liege: IUSSP, pp. 377-88.

- 2003a. Data, models, theory and reality: The structure of demographic knowledge, in Agent-Based Computational Demography: Using Simulation to Improve Our Understanding of Demographic Behaviour, edited by F.C. Billari and A. Prskawetz. Heidelberg: Physica-Verlag. - 2003b. Demography in a new key: A theory of population theory. Demographic Research 9:263-84.

. 2005. Computer simulation and statistical modeling: Rivals or complements? Paper presented at Session 131 (The Epistemology of Demography) of the General Assembly of the International Union for the Scientific Study of Population. Tours, France (available at http:/ /www.iussp.org/France2005).

Coale, A.J., and D. McNeil. 1972. The distribution by age of the frequency of first marriage in a female cohort. Journal of the American Statistical Association 67:743-9.

Cohen, J.E. 2003. Human population: The next half century. Science 302:1172-5.

Coleman, J.S. 1964. Introduction to Mathematical Sociology. New York: Free Press.

Forrester, J.W. 1961. Industrial Dynamics. Cambridge, MA: MIT Press.

. 1971. World Dynamics. Cambridge, MA: MIT Press.

Gotelli, N.J. 1998. A Primer of Ecology. 2nd edn. Sunderland, MA: Sinauer Associates.

6. The discovery that in some biological species the initial response to population growth and increasing density may be an increase in the birth rate and a decrease in the death rate-just the opposite of the assumptions underlying the logistic model, and similar to some historical cases of human population dynamics. See Allee et al. 1949. 
Hanneman, R.A. 1988. Computer-Assisted Theory Building: Modeling Dynamic Social Systems. Newbury Park, CA: Sage Publications.

Hannon, B. and M. Ruth. 1994. Dynamic Modeling. New York: Springer-Verlag.

Hernes, G. 1972. The process of entry into first marriage. American Sociological Review 37:173-82.

HPS (High Performance Systems). 1996. Stella: An Introduction to Systems Thinking. Hanover, NH: High Performance Systems.

Hudson, J.C. 1970. Elementary models for population growth and distribution analysis. Demography 3:361-8.

Keyfitz, N. 1965. On the interaction of populations. Demograpby 2:276-88.

Lotka, A.J. 1934/1939. Analytical Theory of Biological Populations. Translated with an introduction by D.P. Smith and H. Rossert. New York: Plenum Press. [Translation of Théorie Analytique des Associations Biologiques. Première partie, Principes; deuxième partie, Analyse démographique avec application particulière à l'espèce bumaine. Paris: Hermann \& $\mathrm{C}^{\mathrm{ie}}$.]

-1956. Elements of Mathematical Biology. New York: Dover Publications. [First published in 1924 as Elements of Physical Biology.]

Meadows, D.H., D.L. Meadows, J. Randers, and W.W. Behrans III. 1972. The Limits to Growth. New York: Universe Books.

Preston, S.H., P. Heuveline, and M. Guillot. 2001. Demography: Measuring and Modeling Population Processes. Oxford: Blackwell Publishers.

Richardson, G.P. and A.L. Pugh. 1981. Introduction to Systems Dynamics Modeling With Dynamo. Cambridge, MA: Productivity Press.

Roberts, N., D. Anderson, R. Deal, M. Garet, and W. Shaffer. 1983. Introduction to Computer Simulation: The Systems Dynamics Approach. Reading, MA: Addison-Wesley.

Rosero-Bixby, L. and J.B. Casterline. 1993. Modeling diffusion effects in fertility transition. Population Studies 47:147-67.

Smith, J.M. 1968. Mathematical Ideas in Biology. Cambridge: The University Press.

Wilson, E.O. and W.H. Bossert. 1971. A Primer of Population Biology. Sunderland, MA: Sinauer Associates. 